\title{
Paradoxos do Trabalho Prisional na Era do Capitalismo Flexível: o Caso do DETRAN-RS
}

\author{
Silvia Generali da Costa \\ Pedro Luiz da Silva Bratkowski
}

\section{Resumo}

O artigo faz uma análise comparativa entre o significado do trabalho prisional e o significado do trabalho realizado por homens livres. Para tanto, traz a experiência do DETRAN-RS na aplicação de ferramentas gerenciais ao trabalho de sentenciados oriundos dos regimes aberto e semi-aberto, uma iniciativa pioneira no Estado. Tal experiência buscou aproximar a realidade laboral dos apenados da realidade dos demais trabalhadores da instituição. Foi realizada uma pesquisa-ação e uma revisão da literatura crítica sobre o tema. Conclui-se que o mundo corporativo da nova economia não favorece a criação de vínculos e de identidade entre os membros, não sendo um modelo adequado de reinserção social pelo trabalho estável e aderência a rotinas. A estrutura oferecida pelo DETRANRS, mais próxima das burocracias tradicionais, oferece estas possibilidades. A submissão a controles, avaliações e normas preestabelecidas, típica dos modelos clássicos de administração e imprescindível no sistema carcerário, foi avaliada positivamente pelos sentenciados e considerada como forma de valorização profissional.

Palavras-chave: trabalho prisional; capitalismo flexível; significado do trabalho.

\begin{abstract}
The article makes a comparative analysis between the meanings of prison work and free work. For that purpose, it brings the experience of DETRAN-RS at applying management tools to the work of prison inmates serving sentences in open and semi-open regime. This is a pioneer initiative in the state. Such experience sought to approximate the labor reality of prison inmates to the reality of other workers in the institution. An action survey and a review of critical literature on the subject were performed. The conclusion is that the corporate world of the new economy does not favor the creation of links and identity among members, thus not being an adequate model of social reinsertion via stable work and adoption of a routine. Being closer to traditional bureaucracies, the DETRANRS structure offers such possibilities. The submission to control, assessment and pre-established norms, typical of classical management models and essential in the prison system, was positively evaluated by convicts and seen as a way of professional valorization.
\end{abstract}

Key words: prison work; flexible capitalism; meaning of work. 


\section{INTRODUÇÃO}

O artigo tem por objetivo apresentar uma análise crítica e comparativa entre o trabalho prisional e o trabalho livre, a partir da experiência do Departamento Estadual de Trânsito do Rio Grande do Sul - DETRAN-RS. Durante dezoito meses, analisou-se a aplicação de ferramentas gerenciais habitualmente utilizadas em instituições que lidam com indivíduos sem privação de liberdade, bem como os resultados alcançados e suas limitações. As ferramentas aplicadas foram a avaliação de desempenho setorial, a avaliação de desempenho individual, o programa de incentivos e a pesquisa de percepção dos avaliados.

A dimensão e as caraterísticas da estrutura analisada, com grande parte dos recursos humanos oriundos do regime prisional aberto e semi-aberto, bem como em recente livramento condicional, é inédita no Estado e talvez no Brasil, o que justifica a abordagem do tema.

O trabalho está dividido em cinco partes: na primeira, são analisadas as principais críticas ao trabalho prisional, bem como os possíveis significados a ele atribuídos. Na segunda parte, discute-se o trabalho prisional no Brasil. Na terceira, abordase o significado do trabalho realizado por homens livres no contexto da nova economia. A quarta parte apresenta a experiência do DETRAN-RS. A quinta e última parte discute, de forma crítica, os dados apresentados e propõe questões para futuras pesquisas.

A pesquisa é do tipo descritiva exploratória. A metodologia utilizada foi a de pesquisa-ação,

...um tipo de pesquisa social com base empírica, que é concebida e realizada em estreita associação com uma ação ou com a resolução de um problema coletivo, no qual os pesquisadores e os participantes representativos da situação ou do problema estão envolvidos de modo cooperativo e participativo (Thiollent, 2003, p. 14).

A pesquisa-ação se propõe, segundo Chizzotti (2001) "uma ação deliberada visando uma mudança no mundo real, comprometida com um campo restrito, englobado em projeto mais geral e submetendo-se a uma disciplina para alcançar os efeitos do conhecimento" (p. 100).

Os dados coletados foram analisados à luz da literatura crítica sobre o significado do trabalho prisional e do trabalho não-prisional no capitalismo flexível. Os 
resultados da pesquisa de campo indicaram o nível de satisfação dos usuários do novo sistema, bem como da instituição que os abrigou, apontando para os benefícios gerais do trabalho. A análise crítica teceu considerações sobre o significado mais profundo das ações implementadas, bem como de sua contextualização e conseqüências de médio-longo prazo.

Embora Lemos, Mazzilli e Klering (1998) proponham uma distinção entre sistema penitenciário (de caráter mais global, voltado para a reabilitação do condenado) e sistema carcerário (voltado apenas para a guarda do preso), para fins deste trabalho utilizou-se ambas as terminologias no mesmo sentido: como a de um sistema que abriga indivíduos em privação total ou parcial de liberdade, condenados judicialmente por crimes cometidos.

\section{O Trabalho Prisional: Críticas e Possíveis Significados}

O sistema prisional vem sendo questionado desde seu surgimento. "A 'reforma' da prisão é mais ou menos contemporânea da própria prisão. Ela é como que seu programa". (Foucault, 1987, p. 197). O trabalho prisional, como parte deste sistema, também é alvo de críticas e de questionamentos há longa data. Para fins didáticos, foram elencadas as principais críticas em três categorias.

a) O trabalho não reabilita: é uma moeda de troca. Segundo Foucault (1987), o trabalho é visto como um "agente de transformação carcerária", uma maneira de retirar o preso do ócio perigoso que conduz ao vício, ou ainda, uma maneira de criar um apreço e um hábito pela rotina e pelos costumes e de conhecer o senso de propriedade (este fornecido pelo recebimento de um salário em troca do serviço prestado). Seria ainda o acesso a uma ocupação sadia e a um possível caminho de reintegração social. "O trabalho pelo qual o condenado atende às suas próprias necessidades requalifica o ladrão em operário dócil". (p. 204) O trabalho não é uma livre opção dos indivíduos, interessados eles próprios em seu desenvolvimento pessoal na aquisição de habilidades e atitudes coerentes com o mercado de trabalho.

A utilidade do trabalho penal? Não é um lucro; nem mesmo a formação de uma habilidade útil; mas a constituição de uma relação de poder, de uma forma econômica vazia, de um esquema da submissão individual e de seu ajustamento a um aparelho de produção. (p. 204).

Segundo Goffman (2003), o indivíduo submetido involuntariamente a instituições de caráter coercitivo e fechado pode engajar-se no trabalho, a fim de obter um 
ajustamento secundário, ou seja, a possibilidade de participar de uma série de situações que normalmente não seriam toleradas pela instituição que abriga os internos. Aceitar o trabalho demonstraria à equipe carcerária - dirigentes e guardas, todos aqueles que controlam as condições de vida na prisão - a aceitação das normas institucionais e o desejo de "regeneração". Por outro lado, possibilitaria ao preso assumir uma atitude oposta àquela representada pela aceitação voluntária da tarefa, exercendo ele próprio o controle de algumas variáveis ambientais, numa atitude de oposição ao rígido controle institucional. Dispor de tempo para fumar, por exemplo, pode ser uma expressão do autocontrole do tempo e do lazer. Este tipo de instituição foi definida por Erving Goffman (2003), em seu livro Manicômios, Prisões e Conventos, como "instituições totais: um local de residência e trabalho, onde grande número de indivíduos com situação semelhante, separados da sociedade mais ampla por considerável período de tempo, levam uma vida fechada e formalmente administrada" (p. 11).

O ajustamento secundário e o trabalho prisional como mero instrumento de troca por bom comportamento são investigados no artigo Trabalho Prisional Como Política Pública de Recuperação do Criminoso: estudo de múltiplos casos em unidades penitenciárias de Minas Gerais - Brasil, de Ribeiro e Cruz (2002). Os autores concluem sobre a necessidade da vinculação do trabalho prisional a políticas públicas de reinserção social, como forma de transformar as atividades desenvolvidas pelos detentos em algo intrinsecamente significativo.

O estudo de Lemos et al. (1998) confirma o significado de troca, e não de reabilitação, do trabalho prisional. Os autores afirmam que o ingresso dos apenados ao sistema de trabalho tem como objetivo prioritário a redução da pena. "Em raros casos, percebe-se um envolvimento maior dos apenados com o processo produtivo" (p. 139). Os presos percebem a ausência de significado do esquema de trabalho proposto. "Chegam mesmo a afirmar que o trabalho prisional não é trabalho; é só uma maneira de a instituição manter a ordem e a disciplina" (p. 141).

b) O trabalho prisional traz prejuízos à sociedade: o preso que trabalha ocupa uma vaga do desempregado e desequilibra o mercado de mão-de-obra. Embora grande parte da sociedade concorde que o preso deveria trabalhar para "pagar" por sua "estadia" na prisão, cobrindo despesas com alimentação, saúde, etc..., muitos empresários consideram que "... o uso da mão-de-obra encarcerada cria uma concorrência desleal em relação aos que têm de contratar pessoas no mundo livre, a preços muito altos..." (Pastore, 2001, p. 2).

Foucault (1987) relata o conflito entre os trabalhadores franceses desempregados e os defensores do trabalho prisional do período de 1840 a 1845, em plena época de crise econômica. Os argumentos dos que procuravam, em vão, uma colocação 
digna no mercado de trabalho era de que os presos ocupavam as posições de menor periculosidade, de que eram recompensados com salários embora fossem criminosos e de que "é preciso matar ou roubar para poder trabalhar".

No período de recessão e desemprego que o Brasil atravessa, estas críticas parecem ainda atuais. No entanto a socióloga Julita Lemgruber relata que, no período em que dirigiu o sistema penitenciário do Estado do Rio de Janeiro (de 1991 a 1994), procurou estabelecer parcerias com a iniciativa privada para a criação de postos de trabalho no sistema carcerário. As vantagens para o empresariado seriam indiscutíveis: “... o preso deve receber por seu trabalho três quartos do salário mínimo, não é protegido por leis trabalhistas (CLT) e não faz greve". Lemgruber destaca ainda outros benefícios econômicos para os empresários que contratam mão-de-obra prisional: “... o pequeno e médio empresário não paga aluguel pelo espaço que ocupa na cadeia, não paga luz, não paga água nem telefone”. Apesar das aparentes vantagens, “... não foi possível atrair mais do que meia dúzia de empresários para instalar oficinas nas prisões" (Lemgruber, 2003, p. 1).

c) O trabalho prisional é difícil de administrar: a mão-de-obra é perigosa e desmotivada. Como administrar trabalhadores "involuntários"? Como gerenciar uma massa "operária" potencialmente capaz de cometer novos delitos? É possível aplicar ferramentas gerenciais a uma mão-de-obra com antecedentes de violência e, de modo geral, com baixos níveis de escolarização e de qualificação profissional? A experiência do DETRAN-RS procura, pelo menos em parte, responder à esta última questão, conforme será visto a seguir.

Lado a lado com as críticas, continua a conviver no seio da sociedade o desejo de encontrar uma solução para a reabilitação da massa carcerária, evitando as reincidências e o aumento da violência e da criminalidade. Como escreveu Foucault (1987), a sociedade sabe que as prisões e seus modelos de funcionamento são inadequados, mas não "vê" uma forma diferente de funcionar.

As críticas acima não são exclusivas do cenário internacional. A análise da realidade brasileira confirma as dificuldades no gerenciamento e reabilitação de apenados e na diminuição da criminalidade.

\section{O Significado do Trabalho Prisional no Brasil}

Lemos et al. (1998) afirmaram que o trabalho prisional foi instituído a partir da reforma do sistema penal, no século XVIII, com objetivos punitivos. 
No Brasil, o trabalho prisional como forma de punição e controle sobre os indivíduos predominou desde a época do Império até 1937, quando passou a haver preocupação por parte dos juristas e penitenciaristas em instituir uma lei especial para a execução penal (p. 134).

A utilização de mão-de-obra prisional ainda é vista, de certa maneira, como um tabu na sociedade brasileira, sendo que as experiências verificadas são esparsas e restringem-se a trabalhos de unidades de produção em prisões, geralmente em serviços de baixa qualificação.

"Quando falamos em sistema penitenciário o brasileiro é unânime: o preso deve trabalhar durante seu período de reclusão". Foi o que afirmou Oscar Vilhena, secretário-executivo do Instituto Latino - Americano das Nações Unidas (Ilanud), durante o lançamento do Manual "O que as empresas podem fazer pela reabilitação do preso", realizado em 20.11.2001, em São Paulo. Pesquisas do Ilanud mostraram que $90 \%$ da população não quer ver os presidiários ociosos. "As pesquisas de opinião pública, os candidatos a cargos do governo e inúmeras pessoas nas conversas informais defendem a idéia de que os presos devem trabalhar. Muitos acreditam que esse trabalho deve ser duro e penoso" (Pastore, 2001, p. 1). Pastore acrescenta que os motivos pelos quais as pessoas acham que os presos devem desenvolver alguma atividade laborativa são variados e vão do simples castigo à geração de renda para o país.

Julita Lemgruber, Diretora do Centro de Estudos de Segurança e Cidadania da Universidade Cândido Mendes, afirmou que as críticas à ociosidade dos presos são comuns. “....se a Lei de Execução Penal, em vigor há quase 20 anos neste país, fosse cumprida, todos os presos trabalhariam, porque seu Art. 31 é muito claro: 'O condenado à pena privativa de liberdade está obrigado ao trabalho na medida de suas aptidões e capacidades." A socióloga justifica sua afirmativa dizendo que não houve previsão de espaço para o trabalho na arquitetura das novas cadeias construídas. “... o Estado brasileiro tem sido historicamente incompetente para prover trabalho ao preso" (Lemgruber, 2003, p. 1).

A observação de Pastore (2001), reforça as idéias de Lemgruber:

O Brasil não possui uma política explícita voltada para o trabalho prisional, apesar de inúmeros projetos que visam modificar a Lei da Execução Penal insistirem no trabalho com finalidade produtiva e educativa, devidamente remunerado, respeitada a vontade e a aptidão do preso (p. 1).

A sistematização do trabalho prisional, aliada à gestão de recursos humanos para o alcance de metas, parece estar ainda numa fase incipiente. 
A aplicação de ferramentas de gestão em trabalho prisional no Brasil carece da existência de estudos ou bibliografia aprofundada sobre o tema. Em geral, as matérias consultadas revelam algumas similaridades: trabalho dentro do sistema penitenciário, através de implementação de módulos e linhas de produção, com ênfase nas tarefas e baixa autonomia individual, com fortes princípios tayloristas; inexistência de propósitos comuns; objetivo de remissão da pena e da oportunidade de circular dentro do presídio (Hassen, 1999); ausência de formas cooperativas de trabalho; e impossibilidade de hierarquia entre os presos.

Pastore (2001) afirma que no Brasil há cerca de 220 mil presos espalhados entre cadeias e delegacias. Embora não se saiba exatamente quantos destes presos trabalham, sabe-se que as atividades estão concentradas “... nos serviços de limpeza dos pavilhões, pequenos reparos, ajuda na cozinha (...) trabalhos em couro e vime, costura em bolas de futebol, trabalho em móveis e outros - em escala insignificante" (Pastore, 2001, p. 1). De acordo com o autor, a realidade vem-se mostrando diferente nos presídios privados norteamericanos, onde os presos executam tarefas que desenvolverão habilidades potencialmente aplicáveis ao mercado de serviços. Entre elas estariam o telemarketing, o processamento de documentos e a organização de arquivos, e os serviços especializados em eletrônica e telecomunicações (Pastore, 2001b).

Segundo Lemos et al. (1998, p. 136), para que o trabalho prisional possa se constituir numa estratégia de ressocialização, deve levar em conta o "desenvolvimento pessoal dos apenados, utilizando e aprimorando sua capacidade de percepção, bem como suas habilidades, para a resolução de problemas complexos e de serem criativos e inovadores, dentro de um processo real de trabalho", o que ainda está bem distante da realidade na maioria dos países.

Deste forma, quebrar paradigmas no que se refere ao trabalho prisional é ainda um desafio posto para a sociedade brasileira na busca da ressocialização do preso e da diminuição das elevadas taxas de reincidência que são parte da realidade prisional.

Neste esforço insere-se a experiência do DETRAN-RS. A instituição buscou aproximar o trabalho prisional do trabalho livre, lançando mão de ferramentas gerenciais no acompanhamento e avaliação dos trabalhadores oriundos do sistema prisional. Os pressupostos, a evolução do sistema, bem como seus resultados, serão abordados no tópico cinco deste trabalho. 


\section{Notas sobre o Significado do Trabalho de Homens Livres na Era do Capitalismo Flexível}

Quando se discute o significado do trabalho prisional, alguns tópicos são recorrentes: o trabalho para evitar o ócio que leva aos "maus pensamentos" (arquitetar novos crimes, alimentar sentimentos de raiva e de vingança para com a sociedade, aliar-se a elementos de alta periculosidade); o trabalho como fonte de reinserção social (ter papel, função e identidade reconhecidos e valorizados socialmente); o trabalho como fonte de auto-disciplina e de capacidade de aderir a rotinas socialmente úteis (a repetição e a sequiência); e o trabalho como forma de controle social (no sentido estrito, de avaliação da pontualidade e da assiduidade do indivíduo que trabalha e da qualidade do trabalho realizado, e no sentido amplo, proposto por Foucault, 1987 , de controle das almas e sujeição dos corpos).

Os pressupostos das teorias clássicas da administração, expressos nos estudos de Taylor, Fayol e Weber, sugerem a manutenção destes mesmos paradigmas ao trabalho dos homens livres. Weber, com a rotina, a previsibilidade de funcionamento, o apego a normas preestabelecidas, a hierarquia rígida; Taylor com o controle de tempos e movimentos e a separação entre a execução e o planejamento (com o desenvolvimento das primeiras tecnologias gerenciais reconhecidas de sujeição de corpos e mentes); e Fayol com a organização da vida no escritório (Fayol, 1954; Taylor, 1990; Weber, 1978). Os teóricos que sucederam os clássicos teceram críticas justamente ao excessivo controle e submissão que os seus pressupostos representavam sobre os trabalhadores livres.

A teoria administrativa evoluiu. As teorias de transição e as escolas das relações humanas e comportamentalista reconheceram a organização informal, as motivações e necessidades individuais, os sentimentos, as relações de grupo, a necessidade de cooperação e de integração (Morgan, 1996). As escolas posteriores, de abordagem sistêmica e contingencial, chamaram a atenção para a necessidade de integração das organizações com o ambiente externo, gerando novas demandas e habilidades aos indivíduos que nelas labutam.

Com o final do século XX, surgiram novas teorias organizacionais, adaptadas aos conceitos de globalização da economia, capitalismo flexível e novas relações de trabalho. As organizações orgânicas substituem as mecanicistas e as estruturas piramidais são substituídas pelas estruturas em rede. $\mathrm{O}$ homem livre fica, em tese, mais livre: dispõe do seu tempo para o ócio criativo (De Masi, 2000), não precisa mais restringir-se às quatro paredes do escritório, trabalhando de forma virtual, constrói sua própria carreira. Seria o paraíso do trabalhador do século XXI? Rifkin (1995) assegura que não. 
De acordo com o economista, o homem trabalha um número cada vez maior de horas, remontando ao período da revolução industrial, ou está desempregado. O desemprego e a flexibilização dos contratos de trabalho estão a exigir dos trabalhadores cada vez mais qualificação, patrocinada pelos próprios trabalhadores, e a oferecer cada vez menos garantias. Desfazem-se os vínculos com a instituição e trabalha-se por tarefa ou projeto. Não se trata de aproveitar o tempo livre, mas de sofrer com o tempo ocioso, afirma Rifkin (1995). A diferença é que no tempo ocioso não há opções nem recursos para o seu aproveitamento conforme aprouver ao indivíduo. Também não se trata de desfrutar as aventuras da livre iniciativa e do livre mercado, conforme ressalta Forrester (1997), mas de estar à mercê de toda a sorte de incertezas e com o ônus da auto-formação. Para aqueles que não se mostram plenamente aptos ao trabalho flexível da nova economia algumas alternativas: o trabalho terceirizado, de meio expediente, em cooperativas, informal.

Richard Sennet, em seu livro A Corrosão do Caráter: conseqüências pessoais do trabalho no novo capitalismo (2003), conforme o título da obra antecipa, destaca que a falta de visão e de objetivos a longo prazo e a tênue vinculação que se estabelece com as instituições empregadoras (se é que se pode chamar assim) geram alterações nos valores e na noção de identidade dos trabalhadores. A ausência de rotinas e de um círculo de colegas mais ou menos estável, e a necessidade de se estar constantemente aderindo a novos projetos e reinventando a si mesmo, podem gerar crises de identidade de proporções significativas.

Assim, estamos num momento histórico em que os homens livres têm dificuldades em desenvolver vínculos institucionais, de apegar-se a rotinas, de criar uma identidade em torno de sua atividade laboral e não conseguem sequer manter-se empregados (Costa \& Mazzilli, 2001). É neste modelo que espelharemos o trabalho prisional? Ou continuaremos a reproduzir o sistema taylorista, com suas atividades monótonas e repetitivas, inaplicáveis à realidade "extra-muros"? Em parte, a experiência do DETRAN-RS procura integrar estas duas abordagens.

\section{O Caso do Detran-Rs: Buscando uma Nova Abordagem do TrabalHo com Apenados}

Algumas experiências de trabalho são diversificadas pela natureza da atividade ou da tecnologia empregada. Outras, pelo perfil dos trabalhadores e dos consumidores. No entanto, apenas numa parcela muito ínfima dos empreendimentos não haverá uma condição: as pessoas vivendo em liberdade. 
A experiência de gestão com pessoas apenadas revela aspectos que são surpreendentes, quando comparados ao mundo do trabalho corporativo. Ao contrário do senso comum, que aponta que elementos de controle são coercitivos e desalentadores para o moral da equipe, para o apenado o controle e a avaliação são vistos como reconhecimento e valorização do seu trabalho - fatores fundamentais para quem foi julgado e sentenciado por atos que praticou.

O sistema desenvolvido no DETRAN-RS procurou mudar o enfoque vigente no trabalho com apenados, propondo uma visão que vai além da ressocialização de pessoas sentenciadas e da busca da diminuição de pena pelos dias trabalhados. Trata-se de uma mudança de paradigma: busca alcançar resultados, dentro de uma visão de eficiência, paradoxalmente numa autarquia do Estado, utilizando o recurso desta mão de obra atípica.

As ferramentas implementadas no DETRAN-RS trazem um diferencial em relação às demais experiências de trabalho com apenados, sendo que algumas são de certo modo inovadoras até em empresas de excelência na iniciativa privada, como as avaliações da cadeia cliente-fornecedor interno.

Em diversos sentidos, a experiência do DETRAN atende ao sugerido pelo estudo de Lemos et al. (1998, p. 141), de prover aos apenados uma relação mais próxima ao corpo funcional da instituição, um tratamento que os dissocie do crime e os reconheça como "indivíduos portadores de uma história singular e não apenas como criminosos".

\section{Contexto Organizacional e Aplicação das Ferramentas Gerenciais}

O objeto deste trabalho foram as atividades da Coordenadoria de Documentação e Microfilmagem - CEDOC do Departamento Estadual de Trânsito do RGS/ DETRAN-RS. Esta unidade do DETRAN-RS é responsável pela guarda, organização e microfilmagem dos prontuários de veículos e de condutores do Estado, além do arquivo dos processos administrativos gerados na Autarquia. Na época da realização do trabalho encontravam-se armazenados em torno de 80.000.000 de documentos em papel, além de 60.000.000 de documentos microfilmados.

Na CEDOC do DETRAN-RS, os serviços realizados nos setores operacionais são essencialmente de trabalho administrativo, de natureza repetitiva, como organização e pesquisa de documentos. Nos setores de apoio as tarefas são de 
baixa complexidade, como serviços de limpeza, transporte de caixas, manutenção e jardinagem. Além disso, a unidade possui áreas de apoio como planejamento e controle da produção (PCP), psicologia e suporte administrativo.

A CEDOC possuía, em junho de 2003, um total de 65 colaboradores, sendo apenas dois servidores efetivos. Dos restantes, 4 eram estagiários, 3 terceirizados, e 56 oriundos do sistema prisional - do regime aberto e semi-aberto - com baixa periculosidade.

Nos anos de 2000 e 2001, o DETRAN-RS firmou convênios com a SUSEPE e a FAESP, visando à utilização de mão-de-obra prisional para suprir tarefas de cunho operacional, especialmente para a triagem, arquivamento e busca de documentos provenientes das extintas CIRETRANS (Circunscrições Regionais de Trânsito) de todo o Estado.

O trabalho analisado concentrou-se no desenvolvimento de nova estrutura organizacional para a CEDOC, na implantação de avaliação de desempenho individual e setorial, na avaliação de produtividade e na realização de pesquisa de percepção dos trabalhadores apenados e ex-apenados.

\section{Estrutura Organizacional}

A definição da estrutura organizacional foi o alicerce para a aplicação de ferramentas gerenciais que dependiam da criação formal de autoridade e de setores para o suporte e implementação das ações planejadas. A estrutura organizacional, no início das operações da CEDOC, praticamente inexistia como tal, fazendo com que a estrutura informal sobressaísse nas relações de trabalho e nas rotinas operacionais, com o coordenador da área sendo auxiliado por líderes informais, alguns com liderança mais fortalecida em razão de atribuições de maior responsabilidade e pelo papel desempenhado no grupo.

A estrutura proposta visou formalizar, definir e segregar as diversas funções e atividades existentes na Coordenadoria. Logo nas etapas iniciais houve a definição dos setores operacionais e de apoio com o estabelecimento da cadeia clientefornecedor interno, que deu amparo à avaliação de desempenho por resultados. Também foi criada a função de monitor para cada um dos setores, com remuneração diferenciada para esta função: quebrou-se assim um paradigma existente nos trabalhos com apenados, nos quais não haveria essa possibilidade (Hassen, 1999).

A estrutura organizacional adotada, linha-staff, procurou atender às peculiaridades da Coordenadoria, que se caracterizava por previsibilidade das 
técnicas de produção, permitindo definir maior número de liderados por setor. O trabalho de organização e pesquisa de prontuários possui características estruturadas, com procedimentos rotineiros de pouca variabilidade e, portanto, mais fácil de ser planejado e executado. A estruturação mecanicista, com funções e responsabilidades bem definidas também se encontrava presente.

Uma equipe de técnicos especializados na área social, como psicólogos sociais e organizacionais, foi incluída para dar suporte e acompanhamento aos programas implementados, além das atividades de recrutamento e seleção.

O planejamento e o acompanhamento da nova estrutura do setor não eliminaram algumas dificuldades, como a interferência das funções de staff na gestão de linha e a insubordinação de alguns apenados que não aceitaram reportar-se a outros apenados designados monitores, com tarefas retardadas por esta resistência inicial.

\section{Avaliação de Desempenho por Resultados}

Talvez esta seja a ferramenta de gestão mais relevante implementada, seja pelo ambiente onde está inserido - serviço público - seja pelo tipo de mão de obra empregada. Ela está composta por duas variáveis: a avaliação de desempenho setorial e a avaliação de desempenho por produtividade.

\section{Avaliação de Desempenho Setorial}

A avaliação de desempenho setorial foi criada para avaliar os setores cujas atividades não permitem dimensionar a produtividade individualmente, haja vista os trabalhadores desempenharem funções não estruturadas de apoio administrativo e operacional, como nos setores de Serviços Auxiliares e de Movimentação de Arquivo. A avaliação consiste em notas atribuídas ao desempenho dos setores fornecedores internos pelos setores clientes internos.

A avaliação de desempenho setorial, em tese, aproxima-se da avaliação em $360^{\circ}$, na qual, segundo Almeida (1999), um indivíduo é avaliado por seu superior, pelos seus pares, por si próprio (auto avaliação), e algumas vezes até por clientes, com alcance maior que a avaliação individual.

As notas de avaliação setorial durante o ano de 2002 (os últimos 12 meses da pesquisa) tiveram a evolução média de $10 \%$, o que refletiu a melhoria do desempenho dos setores avaliados. A preocupação com a qualidade no serviço tornou-se um item na agenda dos trabalhadores, o que sugere que baixa escolaridade e atuação em tarefas simples e repetitivas não são necessariamente indicadoras de desmotivação e de má qualidade. 
No entanto, algumas limitações na avaliação de desempenho setorial foram observadas, entre elas o alcance restrito em uma unidade (CEDOC), não abrangendo outras unidades do DETRAN e fora do DETRAN que são clientes dos serviços da CEDOC; a possibilidade de ocorrência do efeito halo. Stoner e Freeman (1985) conceituam efeito halo como a maneira de avaliar com notas altas ou baixas todas as medidas de desempenho, tendo por base somente uma das características pessoais do avaliado; e a possibilidade de ocorrerem influências negativas na imparcialidade do método, devido à especificidade da vida de um albergado, que pode vir a compartilhar a residência com um avaliador.

\section{Avaliação de Desempenho Individual}

A avaliação de desempenho individual é a mesma adotada pelo DETRAN-RS para todas as áreas e funções. No caso da CEDOC, esta avaliação possibilitou dar feedback ao avaliado e à administração da unidade a respeito da atuação do colaborador e de sua contribuição para os resultados da Coordenadoria. A avaliação individual também foi utilizada no programa de incentivos, que leva em conta o desempenho individual para a distribuição dos abonos.

A avaliação de desempenho individual foi realizada em períodos de três meses, envolvendo aspectos como iniciativa, responsabilidade, produtividade, disciplina, cooperação, relacionamento interpessoal, pontualidade e assiduidade. A avaliação é do tipo escolha forçada que, conforme Carvalho e Nascimento (1997), consiste na especificação de fatores que compõem determinado cargo, podendo ser denominada também como "sistema de padrões comparativos". São discriminados os critérios e a graduação da avaliação em cada um deles, de maneira a dispor de um instrumento estruturado, sem margens para improvisações, e que permite melhor identificação das diferenças individuais.

Analisando o processo de avaliação de desempenho, notou-se a influência do efeito halo. Por exemplo, um avaliado que realizava com eficiência sua tarefa terminava por receber nota máxima nos outros fatores, mesmo que tivesse problemas de iniciativa ou de relacionamento pessoal, por exemplo. Até fins de 2003, não se fazia um comparativo mais apurado entre a produtividade individual e a avaliação de desempenho, o que poderia fazer com que a avaliação individual não refletisse bem a contribuição do avaliado para os resultados da CEDOC.

A utilização da avaliação de desempenho na CEDOC apresentou limitações em função da ausência do método dos incidentes críticos, que passou a ser aplicado somente em meados de 2003. Como resultado, até este período, inexistia acompanhamento pontual do desempenho, fazendo com que aspectos positivos 
ou negativos do avaliado, ao longo de todo o período, não fossem registrados e considerados na avaliação final.

Apesar das limitações, o processo avaliativo permitiu observar pessoas com potencial de liderança para funções de monitor; dar subsídios para os abonos de produtividade ou de desempenho; ser um fator de motivação enquanto instrumento de feedback; e avaliar o potencial para outros tipos de tarefas, mesmo operacionais, evitando desmotivação ou baixo rendimento no trabalho.

\section{Avaliação da Produtividade}

O controle da produtividade é exercido pelo acompanhamento da produção dos seguintes setores operacionais: Triagem e Procura de Veículos, Procura Habilitação e Triagem Habilitação.

O serviço de triagem faz a organização dos lotes de documentos de veículos e de condutores, através da ordenação pelas letras e números de placa. O serviço de procura faz a busca dos documentos arquivados nas prateleiras, a partir de fichas emitidas pelo PCP (Planejamento e Controle da Produção) da CEDOC, aonde vão especificadas todas as informações pertinentes ao prontuário requisitado.

Na atividade de triagem são contabilizados vários itens referentes à produção de cada setor, sendo que o item utilizado para avaliação da produtividade é a média mensal de lotes organizados por pessoa. Na atividade de procura, por sua vez, além dos vários itens referentes à produção de cada setor, é verificada a média mensal de procuras realizadas por pessoa, que é o item utilizado para avaliação da produtividade.

A análise da sequiência dos dados de produtividade permitiu concluir que houve acréscimo de produtividade em meados de 2002, em pleno processo de avaliação e de incentivos, com percentuais de aumentos que variaram entre 30 e $50 \%$. Em contrapartida, registrou-se um decréscimo de produtividade no período com a avaliação e os incentivos suspensos. Houve mudança de governo, que coincidiu com a falta de pessoal para dar sequiência ao programa e pela demora na nomeação de substituto. Assim, é possível estabelecer uma relação de causa e efeito entre a produtividade e os incentivos neste período. Observou-se ainda um decréscimo da produtividade no último bimestre do ano. O clima de final de ano costuma influenciar o nível de motivação da pessoa apenada, o que deve interferir na produtividade individual.

Segundo Scherkenbach (1990), a avaliação por produtividade também apresenta limitações. Não é possível aumentar sempre a produtividade, uma vez que ela 
depende da estrutura e da tecnologia empregadas. A avaliação por produtividade, por si só, pode deixar a qualidade relegada a segundo plano, comprometendo o resultado do trabalho realizado. $\mathrm{O}$ aumento de produtividade pode ocorrer em relação a valores abaixo da média. Se não for visto o desempenho ao longo de um período maior, qualquer melhoria feita em função de um desempenho medíocre pode distorcer a análise e premiar desempenhos que não atingiriam sequer a média verificada em períodos mais distantes. Os sistemas de premiação com base apenas em metas numéricas não são recomendáveis, porque tendem a punir ou recompensar as pessoas como se elas fossem a única causa do resultado alcançado, sem considerar outros fatores que influirão no desempenho.

\section{Programa de Incentivos}

Os incentivos foram criados para fomentar a motivação individual e de grupo, e eram concedidos de acordo com o acréscimo de produtividade e nível de desempenho. A implantação dos incentivos foi precedida de um diagnóstico que apontou a subutilização do potencial humano na instituição e a baixa motivação para o trabalho, pela inexistência de metas e de cobrança por resultados.

Em virtude das limitações características do setor público, que não favorecem a criação de planos de promoção ou de incentivos financeiros, os incentivos na CEDOC foram concedidos na forma de abonos de ausência, uma espécie de licença remunerada, de acordo com uma tabela que combina o desempenho individual com o desempenho de grupo, para os setores de apoio, sendo que para os setores operacionais os abonos foram concedidos de acordo com a evolução da produtividade média individual em relação ao período anterior. Os abonos garantiram a remuneração em caso de ausência eventual ao trabalho, motivada por passeio ou licença autorizada, aos quais os apenados têm direito, de acordo com a LEP - Leis de Execuções Penais.

\section{Pesquisa de Percepção dos Avaliados}

Foi feita uma pesquisa para levantar a percepção dos colaboradores avaliados em relação à avaliação de desempenho individual e setorial. Os pesquisados não foram identificados, de maneira a tornar o resultado mais fidedigno. O universo pesquisado abrangeu somente colaboradores albergados e ex-albegados. Algumas considerações acerca da percepção destes colaboradores devem ser destacadas. $\mathrm{O}$ processo de avaliação, em linhas gerais, é visto positivamente por parte de quem é avaliado, com índice de $87 \%$ de aprovação, o que de certa forma, não deixa de ser surpreendente. São pessoas que foram, na sua vida, avaliadas, julgadas e condenadas por ações tipificadas como crime pela legislação penal. 
Alguns depoimentos valorizam o reconhecimento dado como decorrência do bom desempenho, que é concretizado na forma dos incentivos. No entanto a subjetividade do processo de avaliação individual vem à tona nos comentários a respeito de eventuais conceitos que valorizariam em demasia desempenhos individuais que não estariam de acordo com a realidade (efeito halo).

Para $25 \%$ dos pesquisados, o processo de avaliação individual é visto como sentença definitiva: se a pessoa serve ou não para a empresa. Não é visto, portanto, como método visando à melhoria do desempenho.

Em relação ao clima que a avaliação individual proporciona, os pesquisados encararam de forma positiva, de maneira geral: $78 \%$ responderam ser uma forma de reconhecimento de seu trabalho, sendo que somente $2 \%$ encararam a avaliação de forma negativa.

No tocante à avaliação de equipe, a maioria dos avaliados se sente reconhecida ou tranqüila. Em caso de resultados negativos, a maior parte da equipe reage pelo incentivo recíproco entre seus membros, a fim de reverter a situação: 64\% dos pesquisados acham que a avaliação deve continuar como está. Pode ser surpreendente este clima de certa forma positivo em relação à avaliação de equipe (apenas 20\% assinalaram sentimentos negativos), visto que seus integrantes são de setores de apoio que são avaliados também pelos monitores dos outros setores internos, portanto um igual, além do coordenador da CEDOC.

Quanto à justiça do cálculo da produtividade, que é feita pela média da produção individual, $62 \%$ entendem que esta medida é justa, não causa prejuízos às pessoas e que o trabalho em equipe é que deve ser avaliado. $38 \%$ consideram que existe injustiça, pelo fato que umas trabalharem mais do que as outras e serem prejudicadas pelo cálculo da média. Isso reflete a subjetividade presente nos cálculos de produtividade em grupo, no qual o resultado final é a soma dos esforços individuais, que não são computados.

Em relação à repercussão de eventuais resultados negativos no moral da equipe, $74 \%$ entendem que os colegas reagem de forma positiva, com incentivo mútuo para reverter a situação. Nesta abordagem, é interessante que em nenhuma resposta houve atribuição de culpa ou conflitos entre colegas na hipótese de baixa na produtividade, segundo os pesquisados. $84 \%$ entendem que a avaliação deve continuar como está, sendo que $63 \%$ consideram que desta forma o setor irá se empenhar sempre. Reitera-se, aqui, o que diz Pontes (2002), para quem é melhor a existência de alguma avaliação de desempenho do que não ter nenhuma, já que a presença de feedback serve de estímulo para a melhoria do desempenho. 


\section{CONCLUSÕES}

Do ponto de vista gerencial, conclui-se que as ferramentas implementadas confirmam na prática a universalidade de princípios de administração que se reproduzem em ambientes organizacionais os mais diversos. O indivíduo, quando motivado e desafiado em face de seus pares e da organização à qual serve, é capaz de melhorias substanciais no seu desempenho. Independentemente do meio social ou da capacidade intelectual, os indivíduos têm aspirações para as quais a organização pode ser a indutora do desenvolvimento, e até mesmo da reinserção social, como é o caso dos albergados e ex-albergados que trabalham para o DETRAN-RS.

No caso do DETRAN-RS, certa autonomia administrativo-financeira da unidade propiciou a implementação de experiências de gestão administrativa; mas aquela, no entanto, não foi suficiente para que estas pudessem ser ampliadas, a fim de favorecer um horizonte profissional às pessoas que participaram deste trabalho.

A avaliação de desempenho setorial, como variante da avaliação de $360^{\circ}$, surgiu como fato interessante, tendo em vista ser uma ferramenta pouco presente, até em empresas da iniciativa privada. Foram observadas mudanças no comportamento das pessoas após o início das avaliações, com a melhoria do desempenho dos setores de apoio, ou fornecedores internos. A avaliação de desempenho pela produtividade possibilitou que setores obtivessem performances nunca antes alcançadas. A avaliação de desempenho individual, para várias pessoas, serviu como um feedback de desempenho e conseqüente aumento no rendimento individual. Também se constatou a importância do programa de incentivos como fator de motivação para o bom desempenho.

No entanto, algumas ferramentas são limitadas no médio e longo prazo, em função das características próprias do setor público. A impossibilidade de se criar um sistema de promoção, por exemplo, inibe a ampliação do programa de incentivos por meio da ascensão por mérito. Outras limitações são próprias dos instrumentos, como a avaliação de desempenho por produtividade com enfoque exclusivamente quantitativo e as avaliações de desempenho, com o efeito halo, que pode comprometer a imparcialidade dos resultados.

No momento pós-montagem da estrutura organizacional, sobrevieram resistências da estrutura informal em função da designação de monitores albergados. Algumas pessoas internalizaram a questão de que "preso não manda em preso", e eram pessoas que tinham uma liderança entre os albergados dentro do sistema prisional e não aceitavam a supervisão de um semelhante. Isso, de 
certa forma, é amostra de como, em muitas ocasiões, a estrutura formal e informal de uma organização são elementos bem distintos.

Para a Autarquia, houve benefícios com o aumento de rendimento dos setores da CEDOC como um todo, com repercussões positivas nas unidades clientes da CEDOC no DETRAN-RS e também em órgãos externos ao DETRAN-RS que necessitam de prontuários de veículos e de condutores para dar continuidade aos seus processos internos. Para os colaboradores albergados, as avaliações e os incentivos distribuídos serviram para enriquecimento do seu trabalho, quem sabe também para a busca de um sentido em suas vidas.

Do ponto de vista da evolução das teorias administrativas, podemos supor que o mesmo sistema burocrático que engessa as ações de recursos humanos e impede incentivos e promoções de acordo com o desempenho, oferece certo grau de estabilidade e permite a criação de uma identidade funcional, o que seria impossível numa estrutura virtual, por projetos de curto prazo. A inserção do apenado numa instituição pública o remete administrativamente às estruturas clássicas, com a previsibilidade de funcionamento, as normas bem definidas, a hierarquia centralizada, os controles formais e, enfim, certo grau de estabilidade das relações, das funções e dos vínculos, muito embora esta mão-de-obra, especificamente, não goze de estabilidade e sequer da possibilidade de permanência a longo prazo. Cabe ressaltar que muitas das tarefas designadas aos presos, de arquivo e controle de documentos, são aplicadas no sistema penitenciário privado norte-americano e consideradas como atividades cujo aprendizado aumentaria o potencial de aproveitamento futuro no mercado de trabalho. Portanto, a CEDOC do DETRANRS teria o diferencial de combinar as vantagens das estruturas clássicas com a preparação para o mercado de trabalho flexível.

A experiência sugere reeditar o experimento de Hawthorne, realizado no período de 1927 a 1933, quando o professor de Harvard Elton Mayo (Maximiano, 2000) comprovou o efeito da valorização humana sobre a produtividade, independentemente das condições estruturais em que o trabalho é operado.

Finalmente, quanto às críticas ao trabalho prisional, pode-se supor que o DETRAN RS se manteve alheio a elas na sua proposta de melhoria do trabalho dos albergados. A instituição buscou simplesmente qualificar o trabalho do apenado, aproximando-o, o máximo possível, do modelo de trabalho do trabalhador livre. Assim, o modelo empresarial foi levado ao cárcere, com suas qualidades e defeitos: de um lado com seus controles e avaliações, com a submissão dos trabalhadores à hierarquia, aos padrões pré-definidos e às normas corporativas; de outro lado, com a estabilidade institucional, a possibilidade de estabelecer relações consideradas sadias, de ver seu trabalho reconhecido, de obter recompensas pelos seus esforços e de criar uma identidade a partir de 
padrões socialmente aceitáveis. Em contrapartida, o cárcere levou seus modelos de funcionamento ao mundo corporativo. A pretensa submissão ao trabalho aparece como possibilidade de troca útil e não somente pelo desejo genuíno de regeneração, e a disciplina é forçada pelas regras do sistema penitenciário, independentemente das regras corporativas, com seus cartões-pontos e sistemas de avaliação.

O DETRAN-RS ofereceu aos sentenciados uma oportunidade de vivenciar o trabalho do mundo dos livres, sem preconceitos ou julgamentos por parte da instituição. Contrariando o ideal de uma parcela da sociedade que busca a segregação do preso, o DETRAN-RS traz o sentenciado para "junto dos seus" e os trata de forma igualitária. Além disso, consegue equilibrar o nível de desafio da tarefa com o nível de capacitação dos presos, com a identificação e aproveitamento de seus potenciais, num ambiente burocrático.

A experiência poderia ser compreendida como integralmente aplicável a diferentes tipos de instituição, não fosse o mundo do trabalho na nova economia tão carente dos valores de lealdade, solidariedade, visão de longo prazo, respeito pelo outro, e cooperação e não estivessem sendo as burocracias tão questionadas pelos arautos do capitalismo flexível.

Algumas perguntas permanecem não respondidas no final deste trabalho. A velha burocracia e as estruturas clássicas são tão indesejáveis ao trabalho dos apenados, e mesmo dos homens livres, como supomos? Os valores ligados a ela, como a estabilidade, a integração do grupo, as metas de longo prazo e a criação de uma identidade institucional não seriam pontos de apoio aos egressos do sistema prisional, intencionalmente despersonalizados em sua passagem pela instituição total? Por outro lado, o trabalho prisional calcado em valores e premissas das estruturas clássicas não se tornaria inadaptável ao mundo do trabalho atual? Esta falta de adaptação do trabalho prisional à realidade da nova economia não impediria a ressocialização dos detentos? Como esperar que a tão atacada burocracia, com suas rotinas e padrões, possa oferecer um padrão de estabilidade aos apenados, se no mundo "extra-muros" ela é considerada tão inimiga da criatividade e da flexibilidade? Como preparar os sentenciados para um mercado de trabalho que talvez nem exista como tal quando eles forem postos em liberdade? De outro lado, não será o mundo corporativo dos homens livres, onde buscamos espelhar o ideal de trabalho prisional, uma espécie de prisão sem grades e sem tempo determinado para a pena, onde os corpos se tornam dóceis e as almas confusas em troca de uma possibilidade de sobrevivência?

Artigo recebido em 21.10.2004. Aprovado em 02.02.2005. 


\section{Referências Bibliográficas}

Almeida, R. O. (1999). Avaliação 360 graus: a melhor intervenção de recursos humanos, será? Recuperado em 15 maio, 2004, de: http://www.perspectivas.com.br/ 360.htm

Carvalho, A. V., \&

Nascimento, L. P. (1997).

Administração de recursos humanos. São Paulo: Pioneira.

Chizzotti, A. (2001).

Pesquisa em ciências humanas $e$ sociais (5a ed.). São Paulo: Cortez.

Costa, S. G., \&

Mazzilli, C.P. (2001).

Programas de demissões voluntárias: uma alternativa ao sofrimento do servidor público? Revista Eletrônica de Administração, 7(5). Recuperado em 11 junho, 2007, de http:// www.read.ea.ufrgs.br

DeMasi, D. (2000).

O ócio criativo (5a ed.). Rio de Janeiro: Sextante.

Fayol, H. (1954).

Administração industrial e geral. São Paulo: Atlas.

Forrester, V. (1997).

O horror econômico. São Paulo: Unesp.

Foucault, M. (1987).

Vigiar e punir: história de violência nas prisões (27a ed.). Petrópolis: Vozes.
Goffman, E. (2003).

Manicômios, prisões e conventos (7a ed.). São Paulo: Perspectiva.

Hassen, M. N. A. (1999).

O trabalho e os dias - ensaio antropológico sobre trabalho, crime e prisão. Porto Alegre: Tomo Editorial.

Lemgruber, J. (2003).

Trabalho nas cadeias. O Globo. Recuperado em 11 de junho, 2007, de http://www.ucamcesec.com.br/mídia/ artigos

Lemos, A. M.,

Mazzilli, C.P., \&

Klering, L. R. (1998).

Análise do trabalho prisional: um estudo exploratório. Revista de Administração Contemporânea, 2(3), 129-149.

Maximiano, A. C. A. (2000).

Teoria geral da administração: da escola científica à competitividade em economia globalizada. São Paulo: Atlas.

Morgan, G. (1996).

Imagens da Organização. São Paulo:

Atlas.

Pastore, J. (2001a, junho 19).

Os limites do trabalho prisional. $O$ Estado de S. Paulo, 19/06/2001. Recuperado em 15 abril, 2004, de www.josepastore.com.br/artigos/ relacoestrabalhistas/140.htm 
Pastore, J. (2001b, maio 22).

O alcance do trabalho prisional. $O$ Estado de S. Paulo, 22/05/2001. Recuperado em 15 maio, 2004, de www.josepastore.com.br/artigos/ relacoestrabalhistas/142.htm

Pontes, B. R. (2002).

Avaliação de desempenho: nova abordagem. São Paulo: LTr.

Ribeiro, L. M. L., \&

Cruz, M. V. G. (2002).

Trabalho prisional como política pública de recuperação do criminoso: estudo de múltiplos casos em unidades penitenciárias de Minas Gerais - Brasil. Anais do Encontro Nacional dos Programas de Pós-Graduação em Administração, Salvador, BA, Brasil, 26.

Rifkin, J. (1995).

O fim dos empregos: o declínio inevitável dos níveis dos empregos e a redução da força global de trabalho. São Paulo: Makron Books.
Scherkenbach, W. W. (1990).

O caminho de Deming para a qualidade e produtividade. Rio de Janeiro: Qualitymark.

Sennett, R. (2003).

A corrosão do caráter: conseqüências pessoais do trabalho no novo capitalismo. Rio de Janeiro: Record.

Stoner, J. A. F., \&

Freeman, R. E. (1985).

Administração. Rio de Janeiro: Prentice-Hall do Brasil.

Taylor, F. W. (1990).

Princípios da administração científica (8a ed.). São Paulo: Atlas.

Thiollent, M. (2003).

Metodologia da pesquisa-ação (12a ed.). São Paulo: Cortez.

Weber, M. (1978).

Os fundamentos da organização burocrática: uma construção do tipo ideal. In E. Campos. (Org. e Trad.). Sociologia da burocracia (4a ed.). Rio de Janeiro: Zahar. 